Expert Witnesses, Dissociative Amnesia, and Extraordinary Remembering:

Response to Brand et al.

Lawrence Patihis $^{1}$, Henry Otgaar ${ }^{2,3}$, and Harald Merckelbach ${ }^{2}$

${ }^{1}$ University of Southern Mississippi

${ }^{2}$ Maastricht University

${ }^{3}$ Catholic University of Leuven, Faculty of Law.

Authors address of correspondence:

Lawrence Patihis, School of Psychology, 118 College Drive \# 5025, Hattiesburg, Mississippi, 39406, USA. Email: L.Patihis@usm.edu

Henry Otgaar, Maastricht University, Forensic Psychology, Department of Clinical

Psychological Science, Faculty of Psychology and Neuroscience, P.O. Box 616, 6200 MD

Maastricht, The Netherlands. E-mail: Henry.Otgaar@maastrichtuniversity.nl

Harald Merckelbach, Maastricht University, Faculty of Psychology and Neuroscience, P.O. Box

616, 6200 MD Maastricht, The Netherlands. E-mail: H.Merckelbach@maastrichtuniversity.nl 


\begin{abstract}
Brand et al.’s (2018) response-as well as previous works by some of the authors—reveal a recurrent and concerning picture of using lengthy, but flawed, arguments to promote the concept of dissociative amnesia. Our focus here is not so much on the weak-to-moderate correlation between measures of trauma and dissociation-we concentrate more on the weak evidence for dissociative amnesia. If triers of fact accept there is a correlation between trauma and feeling depersonalized or experiencing memory errors, we foresee relatively few legal consequences. However, if the leap is made to accept that trauma causes dissociative amnesia (or dissociative identity disorder) then it opens the door to repressed memory testimony being trusted in the courtroom, which in the past has had negative consequences. The problem with the concept and theory of dissociative amnesia is that there is an easy-to-miss claim of extraordinary remembering that contradicts findings and theories in memory research. Incorrect beliefs in such extraordinary remembering that can have severe repercussions in court. We document some areas of agreement with Brand et al., but reiterate that there is a lack of evidence for the mechanisms proposed in dissociative amnesia.
\end{abstract}

Keywords. Dissociation, Dissociative Amnesia, Trauma, Repression, Repressed Memory 
Expert Witnesses, Dissociative Amnesia, and Extraordinary Remembering: Response to Brand et al.

Extraordinary claims require extraordinary evidence Carl Sagan

In Merckelbach and Patihis (2018) we critically evaluated the attempts of Brand et al. (2017a, b) to provide advice to expert witnesses who assist triers of fact in understanding dissociative reactions. One point of departure was the broadly felt consensus in the forensic field that expert witnesses should be transparent about their limits (e.g., Edmond et al., 2017). Over the past years, the focus on limits and error rates of experts has gained momentum because empirical data suggest that overconfidence of expert witnesses may contribute to miscarriages of justice (e.g., Saks \& Koehler, 2005; Imwinkelried, 2018). As a discipline, psychology is not exactly known for its error-free predictions. Quite the opposite is true: on the whole, clinical psychologists attain relatively modest levels of consistency and consensus, which are two important parameters of professional competency (Thomas \& Lawrence, 2018; see also Herman \& Freitad, 2010). One way to encourage professional competency is to stimulate critical feedback and discussions. In this commentary, we argue that Brand et al. (2017a, b; 2018) are overconfident in their theory of trauma causing dissociative amnesia. In courts of law, we caution the acceptance of memory evidence that purportedly was previously blocked by dissociative amnesia mechanisms. Even though the term “dissociative amnesia” refers to forgetting, it is easy to miss that there is an underlying claim of extraordinary remembering. Extraordinary claims require extraordinary evidence (Hume, 1748/1977; Sagan, 1979; Truzzi, 
1978). It is this purported extraordinary remembering that we think should be treated with skepticism in courts of law.

Brand et al. (2018) compared our criticism with that of a minority of researchers "who refuse to accept any evidence favoring global warming, evolution, or the finding that cigarette smoking related to cancer.” (p., 388). Any ad hominem argument is a fallacy, but this one is certainly not going to help potential expert witnesses with an interest in trauma and dissociation. Global warming, evolution, and cancer all are relatively well-defined, have observable consequences, and have plausible mechanisms that are connected to existing science. This is less true for the proposed mechanisms behind recovered memories and dissociative amnesia.

\section{Recovered Memories}

By “recovered memories,” we assume Brand et al. were referring to an experience that was so traumatic that the individual becomes incapable of remembering it (as opposed to ordinary cued remembering following previous difficulty in remembering). In their original paper, Brand et al. (2017b; p. 303) wrote: “Research has established the reliability of recovered memories of trauma.” In their rebuttal, they now summarize their position as follows: "Brand et al. (2017b) stated that recovered memories can be reliable.” (Brand et al., 2018; p. 384). We applaud this cautious shift. Nevertheless, expert witnesses and triers of fact who read Brand et al. (2017a; 2017b; 2018) might take their writings as an argument for accepting recovered memory evidence in court. In the absence of other corroborating evidence in a legal case, this acceptance would be problematic. That is, in the absence of independent evidence, it will be impossible to determine whether recovered memories of events which emerged during therapy—and were previous unknown to the alleged victim—are accurate or the result of suggestive misinformation 
provided during therapy. Emotional content may not reliably indicate memory accuracy (e.g., Laney \& Loftus, 2008).

\section{Falsifiability}

Expert witnesses who emphasize the accuracy of recovered memories appear willing to accept several problematic premises such as the assumptions that trauma can make memories inaccessible (“dissociative amnesia”) and that memories of trauma may be recovered in pristine form through therapy. One key premise concerns dissociative amnesia, the problematic character of which has been discussed throughout the history of psychology. What stands out in such discussions is the unfalsifiable nature of repressed memories or dissociative amnesia. How can one establish that a memory is repressed, and that that blockage is caused by trauma? How can one establish that a traumatic memory is simultaneously stored and yet inaccessible? There are more parsimonious and testable mechanisms for recovered memories, such as ordinary forgetting, cuing, etc.

There is some irony in Brand et al.’s (2018) response to our commentary, in which they lament the "bad old days" of argumentative rhetoric on the topic. In some places it seems as though they indulge in such rhetoric themselves. Illustrative is the way they summarize our argument as being "false memories exist and therefore dissociative amnesia does not exist” (p. 388). Our central point is that there is whole set of assumptions that one must subscribe to when calling a report of memory loss dissociative amnesia. The evidence for this set is too weak (see below) for an expert witness to offer with enough confidence dissociative amnesia as an explanatory concept to triers of fact.

\section{Revisiting the Memory Wars}


Arguing that dissociative amnesia must exist because it is listed in the DSM-5 (American Psychiatric Association [APA], 2013) boils down to an ad verecundiam argument—an argument from authority. The DSM characterizes dissociative amnesia as a disorder involving traumainduced amnesia of autobiographical experiences that are stored in memory and later retrievable. Criticizing the mechanisms that purportedly underlie dissociative amnesia is essentially a reiteration of the issues that were discussed in the repressed memory debates of the last 30 years. This debate continues to be relevant today precisely because of the influence of authors such as Brand et al. (2018), the effectiveness of a small group of authors in embedding dissociative amnesia deep into the DSM, and their success in producing lengthy review articles in favor of the concept. We wonder whether dissociative amnesia being embedded in the DSM-5, is partially responsible for the recent finding that recovered memories in therapy are also still prevalent (Patihis \& Pendergrast, 2019). There is converging evidence that the debate about repressed memories is not over and appears to have shape-shifted into an argument about trauma and dissociation.

We find it telling that in 1994, David Holmes noted that proponents of the idea of repressed memories were already shifting their arguments to focus on dissociation. After searching for research supporting repression, Holmes (1994) wrote, quite prophetically: “In the absence of good laboratory or clinical evidence for repression, proponents of the concept have begun to emphasize dissociation instead. But that is simply another name for repression” (p. 5).

Our reservations about concepts such as repressed memories or dissociative amnesia are shared by many legal psychologists (Kassin, Tubb, Hosch, \& Memon, 2001), research psychologists (Patihis, Ho, Tingen, Lilienfeld, \& Loftus, 2014), memory researchers (Patihis, Ho, Loftus, \& Herrera, in press), and psychiatrists (Pope, Oliva, Hudson, Bodkin, \& Gruber, 
1999; Lalonde, Hudson, Gigante, \& Pope, 2001) and align well with critical reviews that appeared in respected journals (e.g., Brenneis, 2000; Loftus, 2003; Porter, Campbell, Birt, \& Woodworth, 2003; Takarangi, Polaschek, Garry, \& Loftus, 2008; Rofé, 2008; Piper, Lillevik, \& Kritzer, 2008). To compare the authors of these articles to those who deny that there is an association between, say, smoking and cancer is not a fruitful contribution to scientific discussion.

\section{The Evidence for Dissociative Amnesia}

Unlike Brand and colleagues (2018), we find the evidence for the mechanisms proposed in dissociative amnesia and repressed memory too fragile to rely on as an expert witness. For example, Brand et al. (2018) cite Kritchevsky, Chang, and Squire (2004) as evidence for dissociative amnesia. Our understanding of that study is that it addresses functional rather than dissociative amnesia. Kritchevsky et al. interpreted their research within the range of wellresearched memory phenomena. Note also that Kritchevsky et al. did not apply symptom validity measures to their patients to exclude cases of symptom exaggeration, but they do refer to a range of precipitating factors (substance abuse, mild closed head injury, involvement in illegal activity). Importantly, according to the DSM-5, dissociative amnesia involves the storage and subsequent complete blocking of a memory, with the blocking due to trauma, and in such form that the original memory can be accurately retrieved later (because it was stored). Not one case in Kritchevsky et al. meets this description. This critique is true of many other studies purporting to show evidence of dissociative amnesia.

Similarly, Brand et al. (2018) cite Brown et al. (2007) who found that childhood abuse appeared to result into poor memory of early life experiences. Researchers who do not subscribe to the concept of dissociative amnesia would also expect prolonged negative stress to lead to 
memory problems. For example, we value research that has found a link between stress and poor autobiographical memory specificity (e.g., Kleim \& Ehlers, 2008). The concept of dissociative amnesia is redundant here, and research on overgeneralized memory does not provide support for the precise proposed elements of dissociative amnesia (see also Raymaekers, Smeets, Peters, \& Merckelbach, 2010).

Brand et al. (2018) likewise cite Bergouignan, Nyberg, and Ehrsson (2014) as evidence for dissociative amnesia. Bergouignan et al. used disorienting virtual reality scenes to stimulate what they framed as a "dissociative” out of body experience and found that those who saw the events from the first-person perspective remembered these events better than those seeing the events from outside their body. There are many ways to interpret these fascinating results. For example, Bergouignan et al. (2014) discuss their findings as a "striking example of embodied cognition” (p. 4). Alternatively, this research could be explained by the self-reference effect-a well-established memory effect (see also Chiu et al., in press). Still, Bergouignan et al.’s findings do not establish dissociative amnesia (that an event was stored perfectly well, that trauma blocked the memory rendering it inaccessible for a time, and that the event was recalled accurately later). The other findings that Brand et al. (2018) cite as support for dissociative amnesia can be criticized on similar grounds. Our point is: the cited findings are weak anchors, too weak for an expert witness to take dissociative amnesia as an explanatory concept to the courts. If Brand et al. (2018) are so convinced about dissociative amnesia, we invite them to pick and name one study that they feel most establishes the existence and mechanisms of dissociative amnesia, so we might discuss that one study.

\section{The Trauma-Dissociation Link}


We differ from Brand et al. (2018) in our interpretation of research that finds correlations between trauma scales and dissociation scales. Such dissociation scales have items that do ask about current memory problems, but these items do not establish all the elements of dissociative amnesia. For example, the dissociative amnesia subscale of the Dissociative Experiences Scale (Bernstein \& Putnam, 1986; Stockdale, Grideley, Baloghm, \& Holtgraves, 2002)) contains item such as "finding oneself in a place, but unaware how one got there”, "finding unfamiliar things among one’s belongings”, and “no memory of some important personal events (e.g., graduation).” These items certainly do not provide evidence for dissociative amnesia mechanisms such as successful storage, inaccessibility cause by trauma, and accurate retrieval of previously unknown memories. They do not necessarily describe reactions to trauma, either, although sometimes they may be. Rather they reflect self-assessed memory errors that might be the result of ordinary forgetting, weak encoding of the original experience, or forgetting associated with prolonged stress.

One of the problems in articles like Brand et al. (2017a; 2017b; 2018) is the correlational nature of the evidence that is presented for the link between trauma and dissociative symptoms (that is then often used as evidence of dissociative amnesia). We ask Brand et al. (2018) this simple question: is the evidence robust enough to accept a dissociative amnesia defense or recovered memory testimony in a court of law? If that is the case, the authors could say so explicitly without distracting the reader with long discussions about the small correlations between trauma exposure and scores on a dissociative symptoms questionnaire. We accept that trauma may lead to prolonged stress that can impact ordinary memory mechanisms, and may lead to feelings of depersonalization. Nevertheless, we reiterate that memories of trauma that were unknown to the person before therapy (or before the client adopts a belief in the model that 
trauma-causes-dissociative amnesia) should not be trusted in isolation in a court of law. Other, more reliable, evidence should be sought, such as evidence of continuous memory, photographs, medical reports, and historical complaints documented at the time.

Brand et al. (2018; p. 380) state that there are now six studies showing that diagnoses of dissociative disorders can be reliably made with a structured interview. We agree that these studies are informative, although it is unfortunate that they did not find their way to metaanalyses of the type published by, for example, Rettew et al. (2009). Reliability is not a substitute for validity-interrater reliability tells us nothing about the reality of a syndrome. In the Salem Witch trials in Massachusetts, ministers reliably identified women suffering from signs of bewitchment. Similarly, $19^{\text {th }}$ century physicians could reliably come to agree with diagnoses of hysteria. Presumably, physicians in ancient Greece would all agree about imbalances in the four humors of a patient. In addition, depending on the base rate, even high percentages of inter-rater agreement might imply a relatively modest kappa and non-trivial error rates. In their editorial, Freedman et al. (2013; p. 1) give this example: “if an illness appears in 10\% of a clinic’s patients and two colleagues agree on its diagnosis $80 \%$ of the time, the kappa statistic is $0.46(. .$.$) ”. Brand$ et al. (2018) might ask themselves whether similar statistics are realistic for dissociative disorders and if so, what this implies for diagnosing these disorders in a forensic setting (see also Farrell, 2011).

\section{Agreement}

We are happy to find some areas of agreement with Brand et al. (2018). For example, Brand et al. (2018) now write that they do not "take the position that trauma is the sole reason for elevated scores in dissociation measures” (p. 378). And: “the error rate for diagnosing DID using the SCID/SCID-D-R is low, ranging from 4.4. to 11\%” (p. 380), to which we add that error rates 
of the order of $10 \%$ are non-trivial in a forensic setting. Also, they "agreed with Merckelbach and Patihis that false memories can occur" (p. 385). Furthermore, “Those with DID suffer fragmentation of identity but are not, in fact, multiple instances of people” (p. 386) and “multiple sources of information are required for a comprehensive assessment in the forensic context” (p. 386). Furthermore, Brand et al. write that "Individuals falsely alleging dissociative amnesia....do most certainly exist” (p. 388).

We understand that some of our disagreements are a matter of definition. For example, we place close scrutiny on the entirety of the elements that are needed for dissociative amnesia, and we focus on the proposed mechanism for the cause of the forgetting. Without such details, it is easy to frame cases of functional retrograde amnesia as examples of dissociative amnesia, or to assume the causal role of trauma in the forgetting, or to assume that a memory was inaccessible, or to assume that a recalled memory is accurate. We agree that trauma can cause feelings of depersonalization and, via the mechanism of prolonged stress, to memory problems. However, it is the precise nature of those memory problems where we differ from Brand et al.

We are concerned that a full endorsement of the trauma-dissociation doctrine may make expert witnesses overconfident in their statements, clinicians imprudent in their treatment, and patients vulnerable to suggestive misinformation by therapists. We are especially concerned that as a result of this doctrine, patients come to believe that they were abused and that some come to believe they have a scary array of different personalities within them. If we could agree on the idea that stress can lead to memory problems (and/or feelings of depersonalization), and leave behind the old theories of repressed memories and multiple personalities, we would reach a happy compromise. 
The 1990’s saw an epidemic wave of malpractice lawsuits against therapists, criminal trials against parents based on the recovered trauma memories of their children, and defendants claiming repressed memories for their violent behavior. We believe that it is fair to say that an uncritical belief in dissociative amnesia and repressed trauma played a role in many of these trials. It would have helped Brand et al. (2017a) if they had started their article by addressing what we can learn from the limits and errors that became manifest during that period of repressed memory related lawsuits. We reiterate that a key concern with the trauma-causes-dissociation argument is that it can ultimately be used to support claims of extraordinary remembering in a court of law. The claim can be broken down into two components: 1 . that the person was not previously even aware the events happened, and that 2. the memory of very distant past events come back accurately, vividly, and full of detail. We doubt that the extraordinary remembering implicated in dissociative amnesia is a factual phenomenon robust enough to present to juries and judges. If we were to adjust the quote from Carl Sagan we began this article with, we would state that extraordinary remembering requires corroborating evidence in a court of law.

The authors declare that they have no conflict of interest. 


\section{References}

American Psychiatric Association. (2013). Diagnostic and statistical manual of mental disorders (5th ed.). Washington, DC: American Psychiatric Press.

Bergouignan, L., Nyberg, L., \& Ehrsson, H. H. (2014). Out-of-body-induced hippocampal amnesia. Proceedings of the National Academy of Sciences, 111, 4421-4426.

Bernstein, E. M., \& Putnam, F. W. (1986). Development, reliability, and validity of a dissociation scale. The Journal of Nervous and Mental Disease, 174, 727-735.

Brand, B. L., Dalenberg, C. J., Frewen, P. A., Loewenstein, P. J., Schielke, H. J., Brams, J. S. \& Spiegel, D. (2018). Trauma-related dissociation is no fantasy: Addressing the errors of omissions and errors commission in Merckelbach and Patihis (2018). Psychological Injury \& Law, 11, 377-393. https://doi.org/10.1007/s12207-018-9336-8

Brand, B. L., Schielke, H. J., \& Brams, J. S. (2017a). Assisting the courts in understanding and connecting with experiences of disconnection: Addressing trauma-related dissociation as a forensic psychologist, part I. Psychological Injury and Law, 10, $283-297$.

Brand, B. L., Schielke, H. J., Brams, J. S., \& DiComo, R. A. (2017b). Assessing trauma-related dissociation in forensic contexts: Addressing trauma-related dissociation as a forensic psychologist, part II. Psychological Injury and Law, 10, 298-312.

Brenneis, C. B. (2000). Evaluating the evidence: Can we find authenticated recovered memory? Psychoanalytic Psychology, 17, 61-77.

Brown, D. W., Anda, R. F., Edwards, V. J., Felitti, V. J., Dube, S. R., \& Giles, W. H. (2007). Adverse childhood experiences and childhood autobiographical memory disturbance. Child Abuse and Neglect, 31, 961-969. 
Edmond, G., Towler, A., Growns, B., Ribeiro, G., Found, B., White, D., ... \& Kemp, R. I. (2017). Thinking forensics: Cognitive science for forensic practitioners. Science \& Justice, 57, 144-154.

Farrell, H. M. (2011). Dissociative identity disorder: Medicolegal challenges. Journal of the American Academy of Psychiatry and the Law, 39, 402-406.

Freedman, R., Lewis, D. A., Michels, R., Pine, D. S., Schultz, S. K., Tamminga, C. A., ... \& Shrout, P. E. (2013). The initial field trials of DSM-5: new blooms and old thorns. American Journal of Psychiatry, 170, 1-5.

Herman, S., \& Freitas, T. R. (2010). Error rates in forensic child sexual abuse evaluations. Psychological Injury and Law, 3, 133-147.

Holmes, D. S. (1994). Is there evidence for repression? Doubtful. Harvard Mental Health Letter, 10(12), 4-6.

Hume, D. (1748/1977). An inquiry concerning human understanding. Indianapolis, In: Hackett. (Original work published in 1748).

Imwinkelried, E. J. (2018). The best insurance against miscarriages of justice caused by junk science: An admissibility test that is scientifically and legally sound. Albany Law Review, 81, 851-875.

Kassin, S. M., Tubb, V. A., \& Hosch, H. M. (2001). On the 'general acceptance' of eyewitness testimony research: a new survey of the experts. American Psychologist, 56, 405-416.

Kleim, B., \& Ehlers, A. (2008). Reduced autobiographical memory specificity predicts depression and posttraumatic stress disorder after recent trauma. Journal of Consulting and Clinical Psychology, 76, 231-242. 
Kritchevsky, M., Chang, J., \& Squire, L. R. (2004). Functional amnesia: clinical description and neuropsychological profile of 10 cases. Learning \& Memory, 11, 213-226.

Lalonde, J. K., Hudson, J. I., Gigante, R. A., \& Pope, H. G. (2001). Canadian and American psychiatrists' attitudes toward dissociative disorders diagnoses. The Canadian Journal of Psychiatry, 46, 407-412.

Laney, C., \& Loftus, E. F. (2008). Emotional content of true and false memories. Memory, 16, $500-516$.

Loftus, E. F. (2003). Memory in Canadian courts of law. Canadian Psychology/Psychologie Canadienne, 44, 207-212.

Merckelbach, H., \& Patihis, L. (2018). Why “trauma-related dissociation” is a misnomer in courts: A critical analysis of Brand et al. (2017a, b). Psychological Injury and Law, 11, 370-376.

Patihis, L., Ho, L. Y., Loftus, E. F., \& Herrera, M. E. (in press). Memory experts’ beliefs about repressed memory. Memory, 1-6. Published online first October 2018. https://doi.org/10.1080/09658211.2018.1532521

Patihis, L., Ho, L. Y., Tingen, I. W., Lilienfeld, S. O., \& Loftus, E. F. (2014). Are the “memory wars” over? A scientist-practitioner gap in beliefs about repressed memory. Psychological Science, 25, 519-530.

Patihis, L., \& Pendergrast, M. H. (2019). Reports of recovered memories of abuse in therapy in a large age-representative US national sample: Therapy type and decade comparisons. Clinical Psychological Science, 7, 3-21. https://doi.org/10.1177/2167702618773315 
Piper, A., Lillevik, L., \& Kritzer, R. (2008). What's wrong with believing in repression?: A review for legal professionals. Psychology, Public Policy, \& Law, 14, 223-242.

Pope, H. G., Oliva, P. S., Hudson, J. I., Bodkin, J. A., \& Gruber, A. J. (1999). Attitudes toward DSM-IV dissociative disorders diagnoses among board-certified American psychiatrists. American Journal of Psychiatry, 156, 321-323.

Porter, S., Campbell, M. A., Birt, A. R., \& Woodworth, M. T. (2003). "He said, she said": A psychological perspective on historical memory evidence in the courtroom. Canadian Psychology/Psychologie Canadienne, 44, 190-206.

Raymaekers, L., Smeets, T., Peters, M. J., \& Merckelbach, H. (2010). Autobiographical memory specificity among people with recovered memories of childhood sexual abuse. Journal of Behavior Therapy and Experimental Psychiatry, 41, 338-344.

Rettew, D. C., Lynch, A. D., Achenbach, T. M., Dumenci, L., \& Ivanova, M. Y. (2009). Metaanalyses of agreement between diagnoses made from clinical evaluations and standardized diagnostic interviews. International Journal of Methods in Psychiatric Research, 18, 169-184.

Rofé, Y. (2008). Does repression exist? Memory, pathogenic, unconscious and clinical evidence. Review of General Psychology, 12, 63-85.

Sagan, C. (1979). Broca's Brain, Reflections on the Romance of Science. New York: Random House.

Saks, M. J., \& Koehler, J. J. (2005). The coming paradigm shift in forensic identification science. Science, 309, 892-895. 
Stockdale, G. D., Gridley, B. E., Balogh, D. W., \& Holtgraves, T. (2002). Confirmatory factor analysis of single and multiple-factor competing models of the dissociative experiences scale in a nonclinical sample. Assessment, 9, 94-106.

Takarangi, M. K., Polaschek, D. L., Garry, M. A., \& Loftus, E. F. (2008). Psychological science, victim advocates, and the problem of recovered memories. International Review of Victimology, 15, 147-163.

Thomas, R. P., \& Lawrence, A. (2018). Assessment of expert performance compared across professional domains. Journal of Applied Research in Memory and Cognition, 7, 167176.

Truzzi, M. (1978). On the extraordinary: an attempt at clarification. Zetetic Scholar, 1, 11-19. 